\title{
O efeito do ensino de relações grafofonológicas na redução de erros ortográficos na Educação de Jovens e Adultos
}

\section{The effects of teaching graphophonological relations on the reduction of orthographic mistakes in Youth and Adult Education}

\author{
Francisca Aline Almeida SILVA* \\ Ronaldo Mangueira LIMA JÚNIOR**
}

\begin{abstract}
RESUMO: A escrita é socialmente valorizada, pois representa o saber legitimado e também possibilita o acesso aos bens de cultura. Escrever, pautado pelo que orienta a norma ortográfica, torna-se uma necessidade para que o indivíduo realize um uso eficiente da língua e não seja estigmatizado pelo domínio de apenas uma modalidade linguística. Nas várias etapas de ensino, ainda se percebem dificuldades na ortografia; entretanto, com alunos que apresentam uma trajetória escolar irregular, como os da Educação de Jovens e Adultos (EJA), as dificuldades são acentuadas. Este trabalho, portanto, objetiva avaliar os efeitos do ensino das relações grafofonológicas na redução dos casos de desvios à norma na turma de modalidade EJA nível VI (8º $/ 9^{\circ}$ anos). O objeto de análise consiste dos três erros mais frequentes na turma, constatados a partir de investigação diagnóstica, sendo eles o apagamento do $<\mathrm{r}>$ em coda de verbos no infinitivo, a hipercorreção da grafia da coda de verbos terminados em

ABSTRACT: Writing is socially valued, as it represents verified knowledge and enables users to cultural assets. Writing according to orthographic norms is essential for one to make an efficient use of the language and not be stigmatized for having only the oral modality. In the various stages of teaching, difficulties are still detected in spelling; however, with students at an irregular educational trajectory, such as those of the Youth and Adult Education (YAE), the difficulties are even greater. Thus, this study aims to evaluate the effects of the teaching of graphophonological relations in the reduction spelling mistakes in a class of YAE level VI (8th/9th grades). The data consist of the three most frequent mistakes in class, previously verified in a diagnostic data collection, and they were the deletion of $<r>$ in coda of verbs in the infinitive, the supergeneralization of the grapheme used to mark the coda of verbs ending in $[\mathrm{w}]$, and monophthongation of verbs in the perfect tense of the indicative. An action research was carried out with
\end{abstract}

\footnotetext{
${ }^{*}$ Mestre em Letras (PROFLETRAS - UFC). Professora das Prefeituras Municipais de Aquiraz e de Eusébio - CE. ORCID: https://orcid.org/0000-0003-4305-0449. profaalinealmeida@gmail.com.

* Doutor em Linguística. Professor da Universidade Federal do Ceará (UFC). ORCID: https://orcid.org/0000-0002-8610-0306. ronaldojr@letras.ufc.br.
} 
[w], e a monotongação de verbos no pretérito perfeito do indicativo. Trata-se de uma pesquisação com avaliação qualiquantitativa dos dados de pré e póstestes entremeados por atividades interventivas. Os resultados apontaram a pertinência de um trabalho sistematizado com a ortografia a fim de corrigir problemas que tendem a se perpetuar na trajetória escolar dos alunos, uma vez que a quantidade de desvios diminuiu de 103 para 24 após as intervenções. Chegou-se à conclusão de que atividades ortográficas que relacionem os conhecimentos da turma a informações sobre a estrutura e sobre o funcionamento da língua ajudam a reduzir desvios à norma.

PALAVRAS-CHAVE: Ortografia. Educação de Jovens e Adultos. Relações grafofonológicas. qualitative and quantitative analyses of the data, which were a set of pre-tests, intervention activities, and a set of posttests. The results point to the pertinence of systematized work with spelling in order to decrease problems that tend to linger in the educational trajectory of students, for the number of mistakes decreased from 103 to 24 after the intervention. The conclusion is that orthographic activities that relate the knowledge students already have to information on the structure and functioning of the language help reduce deviations from the norm.

\section{Introdução}

A escrita nem sempre existiu, é uma dentre as várias invenções da humanidade. Outros sistemas de escrita, com propriedades, princípios e objetivos distintos, foram criados antes da invenção do alfabeto. Inicialmente, destacavam os registros do significado global da palavra como a escrita pictográfica e ideográfica e, no decorrer da história humana, com a evolução dos sistemas de escrita, observa-se a criação de sistemas que passaram a notar as partes sonoras que compõe as palavras. O sistema de escrita alfabético usado em nosso idioma baseia-se nessa notação.

Se por um lado, em muitas épocas e em muitas civilizações foi possível viver sem escrever, por outro, na nossa, não dominar a escrita pode implicar algumas dificuldades, pois o uso que dela fazemos nas nossas atividades diárias pressupõe uma relação de dependência da qual poucos conseguem escapar. Por isso, também há 
preceitos que estabelecem o que é esperado das pessoas no que se refere ao domínio dessa habilidade.

Logo, entendemos que a escrita ortográfica é uma convenção social criada a partir do sistema de escrita alfabético. O português só fixou uma convenção ortográfica a ser adotada por todos os usuários do idioma no século XX. Tal escrita foi criada como um recurso para possibilitar que todas as pessoas conseguissem interagir de maneira uniforme, sendo compreendidas, embora apresentem variações consideráveis na fala. O domínio da escrita garante acesso aos bens de cultura socialmente valorizados. Dessa forma, não se expressar adequadamente de acordo com o padrão vigente pode gerar estigma já que as convenções estabelecidas são taxativas quanto a grafia correta ou incorreta de uma palavra. Soares (2017) destaca que inseridos, como estamos, em uma sociedade grafocêntrica, as possibilidades de participação econômica, política, social, cultural são possíveis, principalmente, através do domínio da escrita. Nesse contexto, cabe à escola o papel de oferecer ao aluno a capacidade de transitar em todas as esferas sociocomunicativas com relativa autonomia.

Dentre os aspectos que envolvem a língua, o ensino da ortografia, por seu caráter elementar, parece ser entendido como importante apenas no processo inicial de aprendizagem. Olhando por outro prisma a aprendizagem da escrita, temos a Educação de Jovens e Adultos, que é uma modalidade de ensino permeada de especificidades. Ela já pressupõe uma defasagem educacional, visto que, por algum motivo, os alunos tiveram de interromper os estudos ou não os iniciaram no período adequado A aprendizagem, nesses casos, acontece num outro ritmo e o domínio da escrita como forma de inserção social no mundo letrado, e seu nível mais básico - a ortografia - torna-se uma das principais metas dos alunos.

Entretanto, a apropriação da escrita não se torna simples em decorrência de haver regularidades e irregularidades a serem observadas. Assim, nas primeiras tentativas de transcrever para o papel o que se ouve, percebe-se que a relação fonema- 
grafema não é biunívoca. Lemle (2007) apresenta essa relação como um casamento nem sempre monogâmico, pois, apesar de ideal, só se realiza em poucos casos. Sendo a fala a primeira referência de língua, o apoio na oralidade será a estratégia mais usada para realizar essa "transcrição". Partindo desse princípio, observa-se a importância da reflexão sobre o funcionamento da língua como forma de compreender e aprimorar a escrita.

Este estudo buscou avaliar os efeitos do ensino das relações grafofonológicas na redução de casos de desvios à norma ortográfica na escrita de alunos de EJA. De modo específico pretendemos: A) investigar os casos mais frequentes de desvio à norma verificados na escrita dos alunos; B) elaborar e conduzir atividades reflexivas com ênfase na relação grafema-fonema a fim de promover um domínio consciente da norma ortográfica e C) avaliar os efeitos das atividades que propiciam a reflexão sobre o funcionamento da Língua na diminuição de desvios ortográficos.

\section{Escrita e poder}

Diferentemente da fala que não requer sistematização formal para dela fazer uso, ainda que resultante de sistemáticos processos que vão desde os primeiros "gestos" de fala até a articulação de sentenças, a escrita como convenção social não se adquire espontaneamente, mas precisa ser aprendida. Isso fica evidente ao observarmos que há muitas pessoas adultas que não sabem ler nem escrever apesar da exposição, ao longo da vida, a materiais escritos. Numa sociedade de base grafocêntrica, não ter o domínio adequado dessas habilidades implica estar excluído dos bens culturais por ela acessados.

Se no início do século passado a escrita era privilégio de uma elite seleta que podia acessar a esses bens visto que nessa época mais de $65 \%$ da população com 15 anos ou mais era analfabeta, hoje é requisito para muitas atividades cotidianas. Na dinâmica das relações sociais, muitas tarefas podem ser realizadas por uma pessoa 
analfabeta, outras, no entanto, não. É possível tomar um ônibus para ir ao supermercado, localizar a rua onde ele se situa e fazer compras. Todavia, não será capaz de redigir a lista dos produtos que pretende comprar, tarefa que exige o domínio da escrita. Portanto, ela, ao mesmo tempo em que proporciona a inserção das pessoas no contexto letrado, pode ser motivo de discriminação.

A pessoa analfabeta ou semianalfabeta, sobretudo jovem-adulto, consciente da distinção social existente entre essa condição e o alfabetizado, utiliza-se de estratégias variadas para mascarar sua dificuldade. É legitimada pelo senso comum a ideia de que é responsabilidade exclusiva do sujeito a aprendizagem e a utilização da escrita ortográfica da língua portuguesa e esse pressuposto reforça o poder atribuído a quem a utiliza convenientemente. Parece haver um ideário meritocrático que serve para velar os preconceitos e desqualificar os discursos das populações mais empobrecidas. Soares (2017, p.174) reflete o significado da escrita no contexto atual:

As sociedades modernas, porém, são fundamentalmente grafocêntricas; nelas, a escrita está profundamente incorporada à vida política, econômica, cultural, social, e é não só enormemente valorizada, mas, mais que isso, é mitificada (é frequente, por exemplo, a suposição de que na escrita é que está o discurso da verdade, que só a escrita é o repositório do saber legítimo).

É bem verdade, contudo, que essa relevância atribuída à escrita não se encerra na habilidade técnica. Como defende Kleiman (2008), o domínio da escrita enquanto sistema simbólico e enquanto tecnologia é importante para um uso significativo em contextos específicos e com objetivos específicos. Essa capacidade que supera o simples domínio da técnica também é defendida por Kato (2009) quando destaca que o letramento está relacionado à apropriação da escrita incorporando as práticas sociais que a demandam.

O poder atribuído à escrita pressiona o aluno, que não a domina de forma segura, a procurar a escola por acreditar que ao aprendê-la terá acesso aos espaços 
letrados. A língua, segundo Gnerre (1998), é o arame farpado mais poderoso para bloquear esse acesso. $\mathrm{O}$ autor destaca que os cidadãos, apesar de declarados iguais perante a lei, são, na realidade, discriminados já na base do mesmo código em que a lei é redigida (GNERRE, 1998), pois o texto constitucional é produzido de forma tal que muitos não o compreendem. Escrever do modo convencionado, então, além de uma necessidade na sociedade atual, representa o saber e a verdade, é um instrumento de libertação no sentido de que estará desprendido de uma das possíveis situações de constrangimento e exclusão. Por outro lado, concordamos com Bagno (2007) que dominar a variedade culta da língua não provoca a ascensão social das classes marginalizadas, pois as desigualdades têm raízes mais profundas. No entanto, é papel da escola oferecer os subsídios para que todos utilizem a língua em suas diversas variedades, conforme o contexto comunicativo exigir.

Partindo desse pressuposto, não se pode negligenciar a importância da alfabetização a todos, em especial para aqueles que se escondem de situações em que o uso da escrita vai lhes ser cobrado. Em contrapartida, convém não esquecer o abismo existente entre a norma que lhe será exigida e os conhecimentos que possuem apoiados na oralidade a qual fará analogias para associar à escrita. Em muitos casos, a norma linguística ensinada na escola parece uma "língua estrangeira" para os alunos oriundos de ambientes sociais em que utilizam cotidianamente uma variedade do português não-padrão (BAGNO, 2007). Todavia, essa lacuna vai sendo preenchida à medida que se estabelece uma relação entre o conhecimento normativo que se busca e as hipóteses da língua que o estudante já possui.

Uma questão que se impõe, dessa forma, ao tratarmos a escrita diz respeito ao que a escola exige do aluno. Espera-se que ele escreva certo, ou seja, com base na norma padrão da língua. No entanto, nos momentos iniciais da aprendizagem, escrever conforme a regra gramatical pressupõe grande limitação, porque, desconhecendo as particularidades do funcionamento linguístico, o aluno se 
apoia exclusivamente na fala. Para o aluno que está se alfabetizando, uma corresponde a outra sem ressalvas.

Por essa relação direta entre fonema e grafema não se constituir sempre uma verdade, o aluno vai incorrer frequentemente em "erros" e, dentro e fora da escola, eles são utilizados como fonte de censura e discriminação. Muitas vezes a competência textual é confundida com desempenho ortográfico e esses erros cometidos sobrepujam os avanços obtidos pelo aluno (MORAIS, 2008).

A doutrina do erro arraigada na nossa cultura até hoje é preconceituosa, porque desconsidera que o falante foge à norma, impulsionado pelas regras gramaticais próprias internalizadas, as quais são o resultado de seus conhecimentos linguísticos. Observando prioritariamente aspectos socioculturais, as construções diversas da norma são usadas para legitimar o estigma que acompanha quem assim se expressa. No entanto, o erro diz mais sobre o que o aluno já sabe do que o contrário e essas informações valiosas sinalizam o caminho para superá-lo. Trata-se, portanto, de conceitos preconcebidos, idealizações inflexíveis de falantes da norma culta perante aos falantes de outras variantes.

Ao tratar do conhecimento ortográfico, a escola se preocupa muito em verificálo e cria poucas oportunidades para ensinar ortografia. Esquece-se de que os erros são excelentes oportunidades de aprendizagem, diagnosticando as informações que já possuem e direcionando à confirmação ou à exclusão da hipótese formulada. $\mathrm{O}$ enfoque desproporcional dado ao erro possibilita que a aprendizagem ceda lugar ao desestímulo. No caso específico da EJA, as experiências da vida diária já oportunizaram situações de descrédito em função do não domínio da norma, assim sendo, a baixa autoestima desses alunos pode ser facilmente reforçada com uma abordagem errônea.

O analfabeto, principalmente o que vive nas grandes cidades, sabe, mais do que ninguém, qual é a importância de saber ler e escrever, para sua vida como um todo 
(FREIRE, 1991). As necessidades do cotidiano cobram esses conhecimentos para agir no mundo, desde ir e vir a manifestar-se e defender seus direitos, sobretudo quando estes estiverem ameaçados.

O grupo dos que possuem pouca ou nenhuma escolarização experimenta sim limitações ao exercício dos direitos que constituem a cidadania. Nesse âmbito, podemos destacar a relação entre a fala e a escrita. No campo da oralidade, o não alfabetizado pode atuar, mas a escrita é o veículo que documenta, que valida informações, sem ela, fica o dito pelo não dito, uma vez que a possibilidade de rever, de retornar a qualquer momento, de confirmar ou refutar só é possível pela escrita. Sobre os limites impostos pelo seu uso social, Souza (2004, p.355) destaca que

[...] além de espaços cotidianos que exigem o conhecimento de escrita, bancos, hotéis, institutos de previdências, documentos oficiais, o sujeito sem a escrita fica ainda privado de imergir em jornais, revistas, livros, restringindo a construção do imaginário pessoal e social. As restrições tendem ao nível estratégico, entendido como aquele em que há vozes diferentes, falando de questões cotidianas ou mais elaboradas, ao tempo em que permite o cruzamento da própria voz de quem escreve ou lê.

Apesar do valor social atribuído ao texto escrito, não é prudente reforçar a clássica oposição entre ele e a oralidade. Parece haver uma barreira entre ambos em que, de um lado, reside a beleza e a correção e, do outro, a feiura e a imperfeição. Desse modo, ao aprender a ler e a escrever, o aluno passaria de uma cultura a outra. Por esse prisma, parece haver a necessidade da suplantação de uma variedade linguística que lhe é familiar para que em seu lugar desenvolva uma nova variedade que, muitas vezes, causa-lhe estranheza. Importante é que a escola proporcione espaço para que as culturas se entrecruzem e desestimule a ideia valorativa a elas associadas.

A escrita ortográfica convencionada é única, porque necessita de ser compreendida por todos os falantes, independente dos vários aspectos que os distinguem. À escola cabe trabalhar adequadamente com as diversidades e fazer o 
aluno perceber que não há uma forma única de se comunicar e que a sua não está incorreta, ela deve se adequar ao contexto de uso. A instituição de ensino então vai conferir-lhe instrumentos para realização dessa adequação sempre que lhe for necessário.

\section{A escrita ortográfica}

A norma ortográfica se constitui de uma convenção social que unifica a escrita das palavras (MORAIS, 2010) e permite que possamos nos comunicar com mais facilidade. No entanto, as diferenças entre fonema e grafemas precisam ser ponderadas. A possibilidade de escrever tal qual falamos num país com múltiplos falares como o nosso ocasionaria muitas incompreensões.

Como exemplifica Cagliari (1999, p.67),

[...] poderíamos ter publicações que revelassem, pela escrita, as características fonéticas da língua do escritor, mas, sem dúvida alguma, um grande caos tomaria conta da escrita e da leitura. Por exemplo, alguém observando a própria fala poderia escrever coisas como pfsora, psicréta, pótch, parato (prato), drobá (dobrar)... e aí o trabalho de decifração linguística da escrita seria, sem dúvida alguma, uma tarefa extenuante.

Por esse motivo, é necessária a ajuda para que o estudante que apreendeu como a língua funciona, já que é falante dela, aprenda como a norma ortográfica atua. Assim, à medida que o aluno reconhece as estruturas linguísticas básicas - como os morfemas e as classes de palavras -, torna-se apto a refletir sobre a normatização ortográfica, aprimorando o conhecimento acerca da língua escrita e favorecendo o desenvolvimento da competência discursiva.

Grafar as palavras da forma convencionada se torna uma preocupação e, não raramente, gera constrangimento para o usuário da língua porque revela de imediato seu grau de escolaridade (CAGLIARI, 2002). O domínio da linguagem escrita não se dá pela simples aquisição dos signos visuais, mas há a necessidade da apropriação das 
subjetividades inerentes ao código para que a correspondência fonema-grafema não seja percebida erroneamente.

Considerando que o sistema alfabético é uma representação notacional criada com a finalidade de representar os sons da fala humana, seria cômodo pensar que o objetivo foi atingido com êxito. A escrita alfabética que estabelece uma relação direta entre letra e som é apenas o primeiro passo para a escrita ortográfica, pois ela não é suficiente para a comunicação em todos os casos. Se tomarmos como exemplo o Português Brasileiro, perceberemos que há casos de correspondências diretas entre letra (grafema) e sons (fonemas) como " $\mathrm{p}$ ", “ $\mathrm{b}$ ", “ $\mathrm{t}$ ” ( exceto quando é realizado como alofone [tf] ) "d", "f", " $\mathrm{v}$ ", mas há casos em que um fonema é representado por mais de uma letra e uma letra pode produzir vários sons. Sobre essa relação Lemle (2007, p.17) esclarece:

$\mathrm{Na}$ verdade, temos em português pouquíssimos casos de correspondência biunívoca entre sons da fala e letras do alfabeto. Chama-se correspondência biunívoca aquela em que um elemento de um conjunto corresponde a apenas um elemento de outro conjunto, ou seja, é de um para um a correspondência entre os elementos, em ambas as direções.

À medida que o aluno observa a falta de correspondência entre letra e som, inicia-se o período em que necessita de mais ajuda para confirmar ou não suas hipóteses. Lemle (2007) sistematiza a relação entre eles em quatro etapas: a teoria do casamento monogâmico em que há a relação direta de um para um; a teoria com restrições de posição em que a posição condiciona a escolha; as partes arbitrárias do sistema que abriga às idiossincrasias e, por fim, um pouco de morfologia em que aspectos gramaticais são condicionantes da escrita.

Para um auxílio eficiente do professor, é importante entender como se organiza a norma ortográfica da língua. Tomaremos como referência para esse trabalho as contribuições de Morais $(2007 ; 2008)$ que apresenta uma estruturação a partir das 
regularidades e das irregularidades. Segundo ele, existem diferentes critérios por trás da relação entre os sons e as letras. Destaca, no primeiro grupo, três tipos de relações regulares: diretas, contextuais e morfológico-gramaticais. Nas diretas, não existe competição de letras para grafar determinado som, para cada som corresponde uma letra; nas contextuais, o contexto, dentro da palavra, é que vai definir a letra (ou dígrafo) que devem ser usados; e nas morfológico-gramaticais, a compreensão da regra se dá pelos aspectos ligados à categoria gramatical e, p no segundo grupo, das relações irregulares, salienta que não é possível o apoio em regras para decidir o uso desta ou daquela letra.

Neste trabalho, o objeto de estudo foi definido a partir da observação prévia de erros, constatando que estão relacionados aos processos fonológicos, que, por sua vez, são alterações que os fonemas sofrem em determinados contextos durante sua realização. Normalmente acontecem em decorrência da tentativa de facilitar a realização de um som ou grupo de sons. Eles impactam a escrita porque, muitas vezes, são refletidos nela. $\mathrm{O}$ aprendiz, no processo de aprendizagem da escrita, tende a mobilizar, majoritariamente, o conhecimento fonológico envolvido na relação entre fonemas e grafemas, buscando referência na fala para o registro escrito. Dessa influência advêm registros desviantes da norma ortográfica.

Os erros mais recorrentes encontrados em atividades diagnósticas prévias foram os de apagamento do $<\mathrm{r}>$ em coda de verbos no infinitivo, como em "eu vou fala [falar]"; a hipercorreção da grafia da coda de verbos terminados em [w], como em "ele comel [comeu]"; ; a monotongação de verbos no pretérito perfeito do indicativo, como em "ele tomo [tomou]", motivo pelo qual foram selecionados para um tratamento didático. Tratar erros de ortografia relacionados ao aspecto gramatical dos verbos é de suma importância por ser esta uma classe de palavras relevante para $o$ desenvolvimento da habilidade escrita. 
Apoiados no entendimento de que o desempenho ortográfico apresenta relação direta com a exposição aos conceitos e modos de organização da língua, Cagliari (2002), Lemle (2007), Morais (2008) defendem o desenvolvimento da capacidade do aluno pensar sobre as características estruturais da língua e manipulá-las adequadamente. Em um primeiro momento, os conhecimentos fonológicos parecem os mais relevantes para os alunos, todavia com a percepção da insuficiência de análise para todos os casos, já que a unidade grafofônica escapa a algumas situações, inicia-se a procura por relações entre o sistema de escrita alfabético, que é regular pois uma letra registra uma unidade sonora fixa embora várias letras tenham o mesmo valor sonoro e alguns sons sejam notados por letras diferentes, e o sistema ortográfico que possui incongruências irregulares como mencionado anteriormente.

Nas palavras de Morais (2008, p. 39):

No caso da ortografia, concebo que o aprendiz - que, insisto, não é mero repetidor passivo - também reelabora em sua mente as informações sobre a escrita correta das palavras. Esse processo de reelaboração (das restrições da norma) em níveis mais e mais sofisticados o levaria a ser cada vez mais capaz de escrever corretamente, já que seus conhecimentos (sobre regularidades e irregularidades) se tornariam mais explícitos, mais conscientes.

Para Morais (2008), o conhecimento morfológico permite ao aluno inferir o processo gerativo de algumas regras vinculadas a essa categoria, dispensando assim a necessidade de memorizar uma a uma as formas ortográficas. Vários casos de regularidades que geram dúvidas no português brasileiro podem ser absorvidos à proporção que esse conhecimento é aplicado.

Para isso, é necessário um tratamento dispensado à ortografia que não se restrinja a verificar a correção de seu emprego.

Para Morais e Silva (2007, p.61-62) forma como a ortografia é ensinada está diretamente relacionada à concepção que se tem de seu ensino. Segundo esses autores, existem pelo menos três concepções distintas de ensino: a tradicional, a assistemática 
e a reflexiva. A primeira ocorre pela memorização e pela repetição; a segunda caracteriza-se pela ausência do ensino; e a terceira trata o ensino como objeto de reflexão.

A perspectiva tradicional é a mais conhecida e foi/(é?) amplamente utilizada como forma de adquirir o domínio da norma. Cópia, ditado, lista de palavras, incontável repetição de um vocábulo são metodologias empregadas para esse fim. Sob esse prisma, o aluno, por meio de uma atitude passiva e mecânica, não necessitaria refletir sobre os aspectos que envolvem a ortografia. A realização dos comandos seria suficiente para aprender a escrever as palavras.

No polo oposto, há o estudo assistemático, ou seja, a ausência dele. Essa concepção decorreu da crença de que o contato com as palavras, ainda que sem um estudo direcionado, seria suficiente para absorvê-las. Conforme Soares (2017), houve uma confusão entre os conceitos de alfabetização e de letramento ocasionando um abandono do ensino da técnica. Por acreditar que se voltaria ao mecanicismo, desenvolveu-se uma cultura espontaneísta em que o contato com textos e o tempo produziriam alunos competentes ortograficamente.

Diferente de ambas as abordagens, o ensino reflexivo proporciona conhecer a estrutura e o funcionamento da língua. Rego (2007) lembra que é importante destacar a aprendizagem da ortografia não como um processo passivo, mas, contrariamente ativo, já que hipóteses são constantemente elaboradas pelos alunos sobre como se escrevem as palavras de sua língua. A escola precisa, então, ajudar o aluno a compreender como se processam as regras subjacentes à escrita.

Justamente por apresentarem tipos variados de regularidades e de irregularidades, não é possível abordar várias categorias de erros em uma única situação. Cada momento exige um grupo específico de casos e de metodologias adequadas a eles. Os casos que envolvem análise do contexto vocabular não poderiam 
ser ensinados da mesma forma que os casos nos quais a exploração dos conhecimentos morfológicos se faz imprescindível.

É importante destacar que a aprendizagem da escrita ortográfica não é um processo com prazos determinados, mas contínuo, que pode durar a vida inteira. Bortoni-Ricardo (2009) afirma que o conhecimento acerca da ortografia de uma língua desenvolve-se a partir da conscientização sobre os aspectos linguísticos e socioculturais envolvidos na determinação das convenções de escrita. Após a alfabetização, que é o processo inicial de aprendizagem da escrita, há um longo caminho de reflexão sobre a normatização da língua a ser percorrido, por conseguinte, uma atitude espontaneísta em relação a alunos que se encontram em etapas finais do Ensino Fundamental ou Médio só intensifica a dificuldade.

\section{Metodologia}

Por seu caráter intervencionista, esta pesquisa de abordagem qualiquantitativa se insere no modelo da pesquisação. Como procedimento reflexivo e sistemático, tem o propósito de investigar um aspecto da realidade objetivando agir sobre ele e transformá-lo cooperativamente.

Nesse caso, o objeto de investigação são as dificuldades ortográficas apresentadas pela turma de EJA IV dos anos finais do Ensino Fundamental de uma escola pública do município de Eusébio, na Região Metropolitana de Fortaleza, no Ceará, a saber, o apagamento de $<\mathrm{r}>$ em coda de verbos, a monotongação e a hipercorreção da grafia da coda de verbos terminados em [w]. A turma era composta de 20 alunos sendo 11 mulheres e 09 homens com faixa etária variando entre 16 e 48 anos, dos quais 18 frequentavam de fato.

O objeto de pesquisa foi definido a partir do levantamento dos erros ortográficos mais frequentes na turma. Para delimitar esse universo amostral, 
conduzimos duas atividades de coleta: uma escrita semiespontânea (redação) e uma escrita dirigida (ditado).

A escrita espontânea é uma importante fonte de informação sobre os conhecimentos que os estudantes já dispõem, pois, segundo Morais (2007a), ao escreverem seus textos de autoria, os aprendizes demonstram, de forma muito genuína, as representações que estão elaborando sobre a ortografia. Portanto, esse é um instrumento que possibilita perceber as necessidades mais urgentes da turma.

Em relação ao ditado, o autor esclarece que quando usado não para ensinar ortografia, mas para diagnosticar pontualmente o domínio das correspondências somgrafia, ele pode ser bastante produtivo. Suas vantagens estão relacionadas à praticidade e à economia com que é possível mapear uma turma.

A primeira atividade diagnóstica consistia no reconto de um cordel apresentado na forma de um curta-metragem intitulado "O coronel e o lobisomem". A segunda consistia em um preenchimento de lacunas de versos de um cordel adaptado cujo título era "O roubo do Banco Central". A escolha dos versos suprimidos da segunda atividade considerou os contextos grafofonológicos que apresentavam mais dificuldades de escrita conforme revelado na redação.

De posse das informações sobre os erros de escrita mais comuns à turma, fez-se necessário realizar intervenções pedagógicas para ajudar os alunos a superá-los. Acreditamos que ao desenvolver um tratamento didático construído a partir das dificuldades manifestadas pelos discentes, considerando o conhecimento que já dispõem sobre as situações de escrita em questão, promoveremos um domínio mais consciente do sistema ortográfico e a redução dos erros observados.

Desse modo, diante dos dados obtidos por meio da verificação diagnóstica, foram realizadas seis intervenções, sendo duas para cada situação de escrita, quais sejam: apagamento do $<\mathrm{r}>$ em posição de coda, a hipercorreção da grafia da coda de verbos terminados em [w] e monotongação do [ow] em verbos do pretérito. Nesses 
momentos, objetivou-se analisar as situações de uso da língua, de modo a refletir sobre os erros e a considerar as diferenças entre a fala e a escrita.

As atividades desenvolvidas constituíram-se de identificação de erros em textos de gêneros variados (texto informativo, lenda, trechos de redações próprias), de reescrita de vocábulos grafados incorretamente, de análise da escolha da escrita relacionando-a ao gênero em questão (cartum humorístico $X$ anúncio), de preenchimento de cruzadinha, de confecção de listas de atividades diárias, de elaboração coletiva de regras a partir da observação/comparação das ocorrências, de observação da pronúncia de sons em letra de música e na fala da turma, de preenchimento de lacunas em fábula, crônica e letra de música e de bingo de palavras. As atividades na íntegra estão disponibilizadas em uma apostila em PDF para utilização e adaptação no link [será incluído na versão final para garantir o anonimato da revisão]".

Concluídas as atividades interventivas, fazia-se necessário averiguar a eficácia do tratamento dados aos erros apresentados pelos alunos. Para constatarmos se houve uma minimização dos casos de erros estudados, procedemos ao pós-teste, que, semelhante ao diagnóstico, compreendeu uma produção semiespontânea e outra dirigida.

A produção semiespontânea constituiu-se de um texto narrativo a partir de um cartum não verbal de Quino. A atividade dirigida consistiu no ditado de frases divididas em três grupos: provérbios populares (brasileiros), provérbios chineses e frases bíblicas.

Todo o corpus foi recolhido para análise dos erros ortográficos e comparação com os dados coletados na avaliação diagnóstica. Foram contabilizados somente os dados referentes a alunos que participaram de todas as etapas das atividades. Dessa forma, dos vinte alunos matriculados, somente doze deles se encaixaram nesse critério e tiveram seus dados considerados. 


\section{Resultados}

Interessava-nos os erros ortográficos de motivação fonético-fonológica em função da recorrência percebida na escrita dos alunos. Para classificar os erros ortográficos influenciados pela oralidade presentes nos textos, utilizamo-nos das categorizações dos processos fonológicos e de relações grafofonológicas propostas por Cagliari (2002) e Roberto (2016). Nesse primeiro momento, no entanto, listamos todos os tipos de erros verificados nos textos. O quadro a seguir apresenta os dados quantificados.

Quadro 1 - Erros por número de ocorrência - pré-teste (redação).

\begin{tabular}{|l|l|c|}
\hline Tipos de erro & Escrita do aluno & Quantidade \\
\hline $\begin{array}{l}\text { Apagamento do } \\
\text { <r>em coda }\end{array}$ & $\begin{array}{l}\text { Coloca, volta, paga(3), coupa, cerca, cria, } \\
\text { cuida(2) arca, olha, fica, da }\end{array}$ & 14 \\
\hline $\begin{array}{l}\text { hipercorreção da } \\
\text { grafia da coda de } \\
\text { verbos terminados } \\
\text { em [w] }\end{array}$ & $\begin{array}{l}\text { Abril (2), resovel, casol(2), aparescel, } \\
\text { ouvil(3), vil, partil, nasel, chamol }\end{array}$ & 13 \\
\hline $\begin{array}{l}\text { Monotongação } \\
\text { assusto, vingo, apago, mando(2), entro, } \\
\text { falo, grito, mato, atiro }\end{array}$ & 10 \\
\hline $\begin{array}{l}\text { Co-ocorrência de } \\
\text { vários grafemas } \\
\text { para o fonema /s/ }\end{array}$ & $\begin{array}{l}\text { apareseu, nareu, naceu, } \\
\text { cresente(1), acontescendo }\end{array}$ & 6 \\
\hline $\begin{array}{l}\text { Co-ocorrência de } \\
\text { vários grafemas } \\
\text { para o fonema /z/ }\end{array}$ & Lobizome (3) belesura, prejuísos (2) & 6 \\
\hline $\begin{array}{l}\text { Alçamento } \\
\text { vocálico }\end{array}$ & lubizome(3), lobizomi, chicotiar & 5 \\
\hline $\begin{array}{l}\text { Co-ocorrência de } \\
\text { grafemas para os } \\
\text { róticos }\end{array}$ & $\begin{array}{l}\text { Caregou, morendo, corronel, aretado, } \\
\text { poradas }\end{array}$ & 5 \\
\hline $\begin{array}{l}\text { Hipossegmentação } \\
\text { grafemas para } \\
\text { representar a } \\
\text { nasalidade }\end{array}$ & $\begin{array}{l}\text { Emtrou, porisso, derepente(2), comedo } \\
\text { comtando acomteceu, jumto, }\end{array}$ & 5 \\
\hline
\end{tabular}




\begin{tabular}{|l|l|c|}
\hline $\begin{array}{l}\text { Registro } \\
\text { inadequado para } \\
\text { lateral em coda }\end{array}$ & Auguém, coupa, coroneu(2) & 4 \\
\hline $\begin{array}{l}\text { Registro } \\
\text { inadequado de } \\
\text { obstruintes }\end{array}$ & Feros, critos, critando, infelismente & 4 \\
\hline $\begin{array}{l}\text { Abaixamento } \\
\text { vocálico }\end{array}$ & Vio(1), saio, escoro, coroneo & 4 \\
\hline Desnasalização & Bateiro, lobisome (2) & 3 \\
\hline $\begin{array}{l}\text { Hipersegmentação } \\
\text { Na quela, em pregado, } \\
\text { a contescendo }\end{array}$ & 3 \\
\hline Nasalização & muinto & 1 \\
\hline $\begin{array}{l}\text { Ausência de } \\
\text { registro do } h\end{array}$ & havia & 1 \\
\hline
\end{tabular}

Fonte: dados da pesquisa.

Esses primeiros dados permitiram-nos perceber as dificuldades ortográficas que são comuns à turma. A partir deles, identificamos quais dos relações grafofonológicas em questão representavam maior interferência na escrita dos alunos. Foi possível constatar que o apagamento do $<\mathrm{r}>$ em coda dos verbos no infinitivo corresponde ao erro mais recorrente, a hipercorreção da grafia da coda de verbos terminados em [w] é o segundo mais frequente, na sequência, temos a monotongação de verbos no pretérito perfeito do indicativo. Os três casos foram, portanto, selecionados para um tratamento didático que permitisse aos alunos a redução dessas dificuldades.

O gráfico a seguir apresenta a quantidade de erros para cada uma das relações grafofonológicas em cada um dos testes diagnósticos. 
Gráfico 1 - Comparativo do percentual de erros por fenômeno nos diagnósticos iniciais

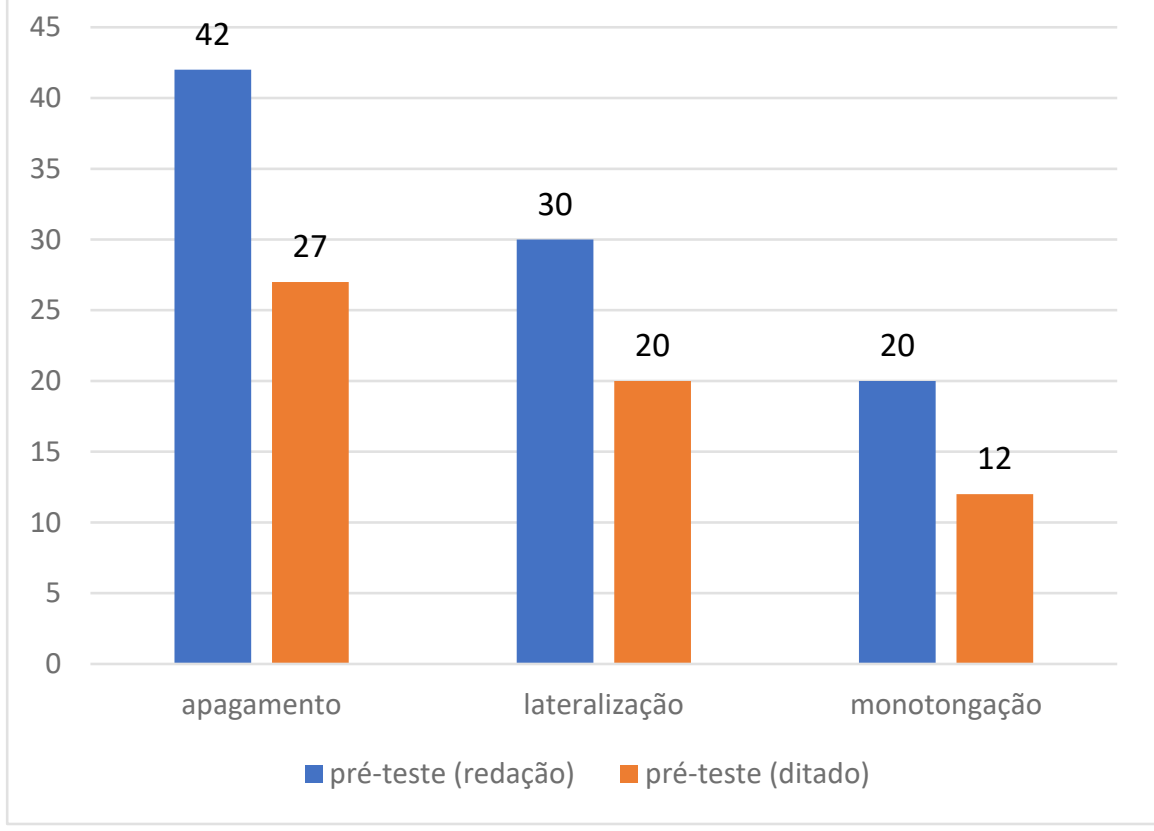

Fonte: dados da pesquisa.

Os resultados apresentados no gráfico evidenciam a necessidade de diagnósticos complementares, pois enquanto o ditado proporciona uma investigação direcionada a situações específicas e, por isso, é mais mecânico, a produção de texto possibilita um leque maior de observação. Por outro lado, na redação, as opções estão restritas aos aspectos que envolvem o tipo de texto solicitado, não garantindo, assim, que todos os problemas ortográficos se revelem, além de os alunos poderem intencionalmente evitar formas sobre as quais têm dúvidas. As informações apresentadas no gráfico ratificam as limitações dos alunos relativas à hipercorreção da grafia da coda de verbos terminados em [w]e monotongação e, sobretudo, demonstram que o apagamento do $<\mathrm{r}>$ causa insegurança na maioria dos alunos visto que, de acordo com a tabela anterior, apenas dois alunos não cometeram esse desvio. 
Diante do exposto, sintetizamos os dados coletados por meio das atividades de diagnóstico na tabela a seguir detalhando o desempenho por aluno.

Tabela 1 - Comparativo dos erros por aluno no diagnóstico inicial.

\begin{tabular}{ccccc}
\hline Aluno & $\begin{array}{c}\text { Pré-teste } \\
\text { (redação) }\end{array}$ & $\begin{array}{c}\text { Pré-teste } \\
\text { (ditado) }\end{array}$ & Total & \% \\
Aluno 01 & 14 & 16 & 30 & 79 \\
Aluno 02 & 6 & 5 & 11 & 26 \\
Aluno 03 & 3 & 9 & 12 & 50 \\
Aluno 04 & 5 & 4 & 9 & 30 \\
Aluno 05 & 2 & 11 & 13 & 40 \\
Aluno 06 & 4 & 7 & 11 & 28 \\
Aluno 07 & 1 & 8 & 9 & 41 \\
Aluno 08 & 2 & 2 & 4 & 12 \\
Aluno 09 & 0 & 0 & 0 & 0 \\
Aluno 10 & 0 & 1 & 1 & 3 \\
Aluno 11 & 0 & 3 & 3 & 9 \\
Aluno 12 & 0 & 0 & 0 & 0 \\
Total & $37(23 \%)$ & $64(18 \%)$ & 103 & 26 \\
\hline
\end{tabular}

Fonte: dados da pesquisa.

Finalizados os procedimentos interventivos, os dados do pós-teste foram confrontados com os obtidos no pré-teste. Dessa análise resultaram as informações apresentadas na tabela a seguir.

Tabela 2 - Comparativo dos erros por aluno no diagnóstico final.

\begin{tabular}{rcccc}
\hline Aluno & $\begin{array}{c}\text { Pós-teste } \\
\text { (redação) }\end{array}$ & $\begin{array}{c}\text { Pós-teste } \\
\text { (ditado) }\end{array}$ & Total & $\%$ \\
\hline Aluno 01 & 1 & 2 & 3 & 9 \\
Aluno 02 & 3 & 1 & 4 & 11 \\
Aluno 03 & 1 & 1 & 2 & 6 \\
Aluno 04 & 2 & 0 & 2 & 6 \\
Aluno 05 & 3 & 2 & 5 & 13 \\
Aluno 06 & 1 & 1 & 2 & 6 \\
Aluno 07 & 3 & 2 & 5 & 13 \\
\hline
\end{tabular}




\begin{tabular}{lcccc}
\hline Aluno 08 & 0 & 0 & 0 & 0 \\
Aluno 09 & 0 & 0 & 0 & 0 \\
Aluno 10 & 0 & 1 & 1 & 2 \\
Aluno 11 & 0 & 0 & 0 & 0 \\
Aluno 12 & 0 & 0 & 0 & 0 \\
\hline Total & $14(4 \%)$ & $10(9 \%)$ & 24 & 5 \\
\hline
\end{tabular}

Fonte: dados da pesquisa.

Como pode ser visto, houve uma redução de um total de 103 desvios nas atividades diagnósticas para apenas 24 nas atividades do pós-teste, o que representa uma diminuição de $77 \%$. Todos os alunos apresentaram uma evolução significativa observável nos dados da tabela. Quatro deles não cometeram nenhum erro ortográfico do tipo analisado nesta pesquisa, os demais reduziram a quantidade. Cada aluno evoluiu de maneira específica a partir das dificuldades manifestadas no início da investigação.

Os três gráficos que se seguem apresentam um comparativo dos percentuais de erros em cada momento, distribuídos por fenômeno.

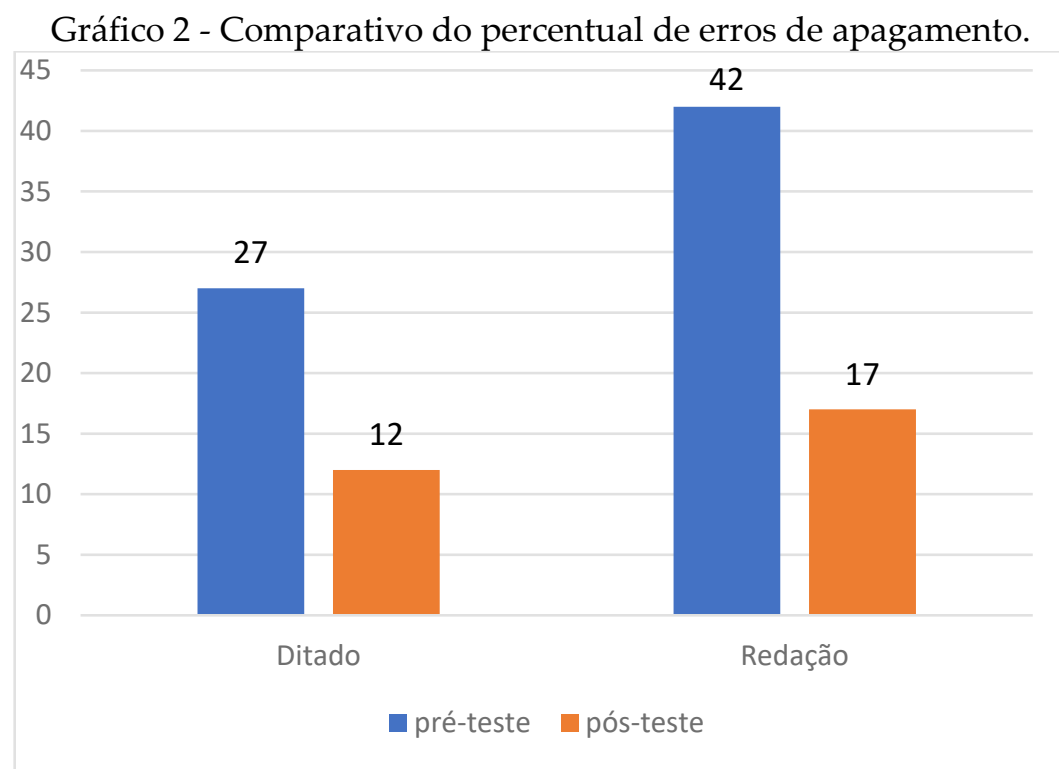

Fonte: dados da pesquisa.

O apagamento do $<$ r $>$ em coda foi observado em maior número de ocorrência e esteve presente na escrita de mais de $80 \%$ da turma. Como os dados demonstram, 
houve uma queda considerável no número de ocorrência, de $27 \%$ e $42 \%$ para $12 \%$ e $17 \%$ no ditado e na redação, respectivamente. $\mathrm{O}$ apagamento se revela resistente ao tratamento didático em função do uso frequente em todas as camadas sociais, eem situações de pouco monitoramento, ele pode ser percebido. Mesmo assim, houve efeito positivo das intervenções.

Gráfico 3 - Comparativo do percentual de erros de hipercorreção da grafia da coda de verbos terminados em $[w]$.

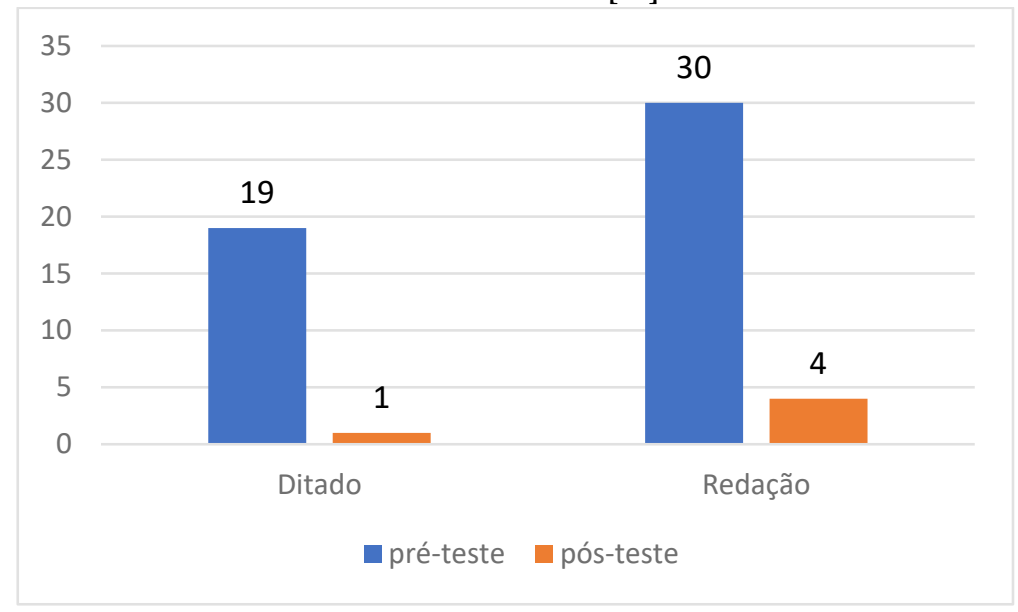

Fonte: dados da pesquisa.

A hipercorreção da grafia da coda de verbos terminados em [w], apesar de menos frequente, representava uma dificuldade comum a metade da turma, cuja intervenção se mostrou bastante satisfatória. A redução dos erros de 19\% e 30\% para $1 \%$ e $4 \%$, respectivamente, sinaliza um resultado condizente ao esperado. Esse caso nos pareceu menos complexo, já que ao lateralizar o último fonema do verbo, produzia-se outro verbo inexistente na língua portuguesa, diferentemente do que ocorre com as outras duas relações grafofonológicas investigadas. À medida que o aluno, de posse do conhecimento morfológico de que há uma única terminação para esses casos, reconhece aquele vocábulo como um verbo no tempo pretérito, as chances de representar a essas codas com $<\mathrm{l}>$ diminuem. 


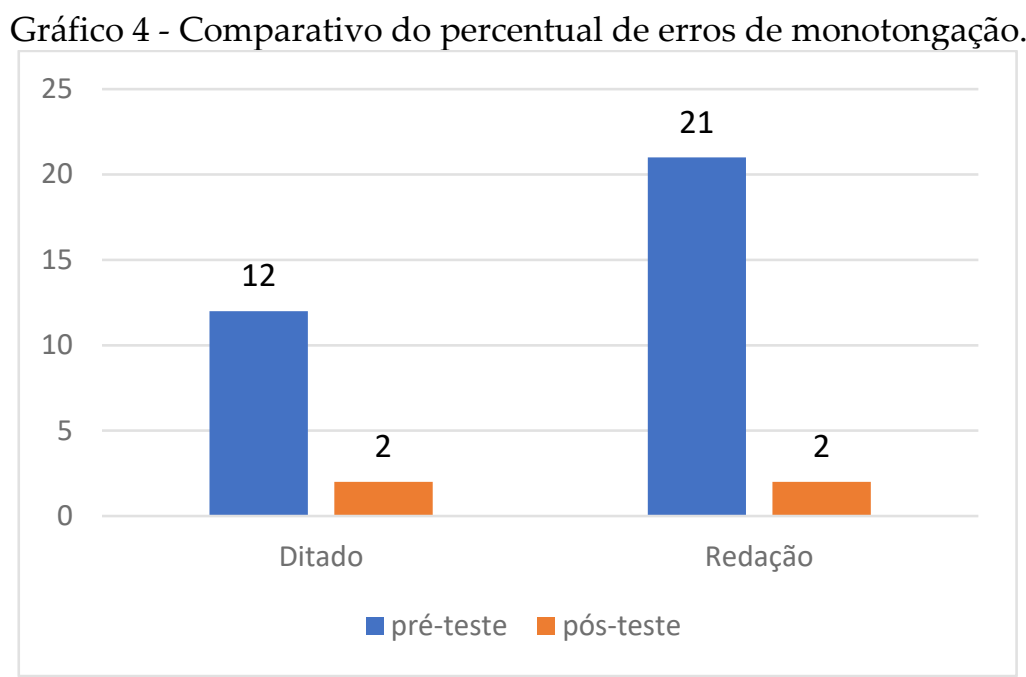

Fonte: dados da pesquisa.

A monotongação, por utilizar-se do mesmo conhecimento morfológico da hipercorreção da grafia da coda de verbos terminados em [w], embora reflita na escrita de uma forma diferente, também apresentou resultados bastante positivos. Houve redução de $12 \%$ e $21 \%$ no ditado e na redação, respectivamente, para apenas $2 \%$ em ambas tarefas.

Os números revelam uma redução considerável na ocorrência da hipercorreção da grafia da coda de verbos terminados em [w] e da monotongação manifestados na terceira pessoa do singular em verbos do pretérito perfeito do indicativo. Nos póstestes, esses erros foram pouco observados. Já no apagamento do $<\mathrm{r}>$ em posição de coda dos verbos no infinitivo, percebe-se uma redução importante no número de casos embora seja esse um fenômeno que exija um tratamento continuado.

A seguir apresentamos um gráfico com o comparativo do percentual de desvios por aluno. A análise do gráfico permite perceber a evolução dos alunos, uma vez que 
há uma considerável redução na quantidade de erros verificados nas atividades de pós-teste.

Gráfico 5- Comparativo da porcentagem de erros pré-teste x pós-teste por aluno.

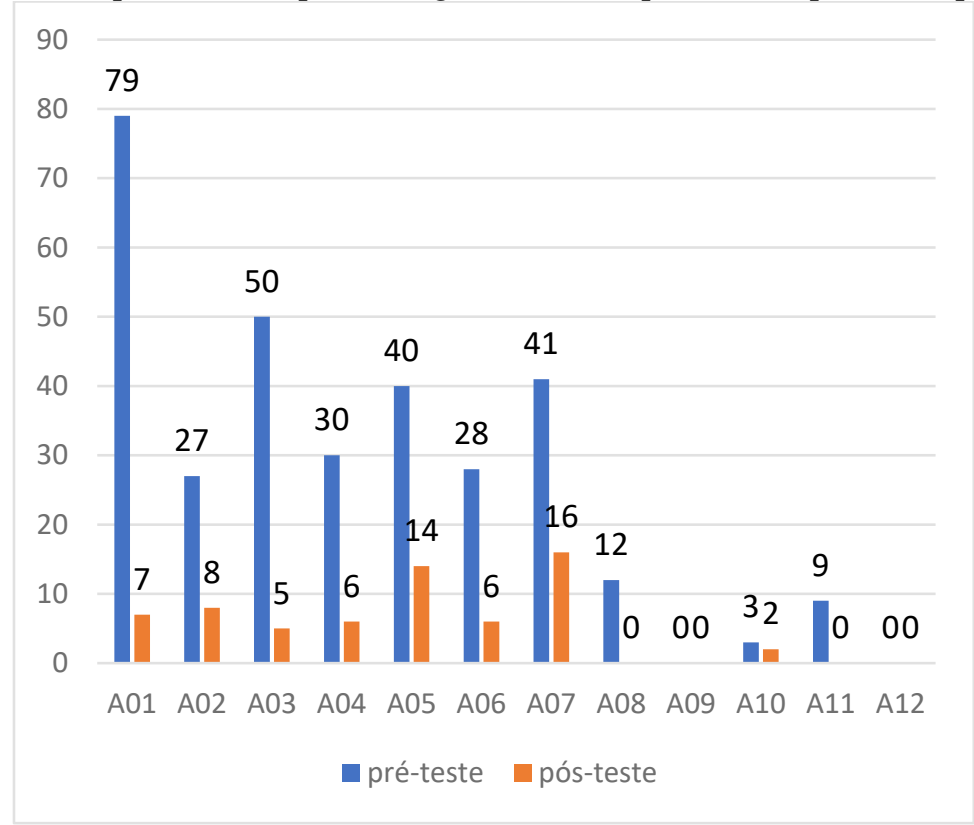

Fonte: dados da pesquisa.

Para dimensionar o impacto das intervenções no domínio das regularidades ortográficas em estudo, apresentamos a seguir uma tabela que apresenta os percentuais de desvios levando-se em consideração todas as ocorrências encontradas, tanto de utilização correta como incorreta de verbos nos casos investigados.

Tabela 2 - Comparativo da porcentagem de erros (pré-teste x pós-teste) por aluno

\begin{tabular}{ccccccc}
\hline \multirow{2}{*}{ Aluno } & \multicolumn{3}{c}{ Pré-teste } & \multicolumn{3}{c}{ Pós-teste } \\
\cline { 2 - 7 } & Erros & Acertos & \% de erros & Erros & Acertos & \% de erros \\
\hline 01 & 30 & 8 & 79 & 3 & 44 & 7 \\
02 & 11 & 28 & 26 & 4 & 47 & 8 \\
03 & 12 & 12 & 50 & 2 & 38 & 5 \\
04 & 9 & 21 & 30 & 2 & 36 & 6 \\
05 & 13 & 20 & 40 & 5 & 30 & 14 \\
06 & 11 & 28 & 28 & 2 & 35 & 6 \\
07 & 9 & 13 & 41 & 5 & 27 & 16 \\
\hline
\end{tabular}




\begin{tabular}{ccccccc}
\hline 08 & 4 & 30 & 12 & 0 & 41 & 0 \\
09 & 0 & 32 & 0 & 0 & 36 & 0 \\
10 & 1 & 37 & 3 & 1 & 42 & 2 \\
11 & 3 & 32 & 9 & 0 & 36 & 0 \\
12 & 0 & 36 & 0 & 0 & 45 & 0 \\
\hline Total & 103 & 297 & 26 & 24 & 457 & 5 \\
\hline
\end{tabular}

Fonte: dados da pesquisa.

Análogas às informações contidas no gráfico anterior, os valores percentuais ratificam os resultados satisfatórios demonstrados ao longo dessa seção. O número variado do total de verbos usado por cada participante é consequência da escolha vocabular que compôs cada redação. Apesar de desenvolverem seus textos a partir da mesma proposta, há alunos que fizeram uso mais produtivo de verbos no infinitivo e na terceira pessoa do singular do tempo pretérito que outros. Os resultados apontam, portanto, para um aumento do domínio das regularidades morfológico-gramaticais exploradas neste trabalho.

Todas as dificuldades apresentadas pelos alunos possuem igual importância, no entanto, cada caso tem sua especificidade. No conjunto diverso de conhecimentos que é comum à EJA, há situações mais preocupantes pela quantidade e pela variedade dos erros detectados. No universo em questão, mais de $50 \%$ da turma apresentou no diagnóstico dificuldades consideráveis, todavia destacamos os alunos 01, 03, 05 e 07, cujos percentuais de erros chamaram-nos muito a atenção.

Dentro desse grupo, o primeiro aluno representava o caso mais extremo, pois dos 38 possíveis usos que compunha o corpus investigado ele errou 30, o que corresponde a $79 \%$ das ocorrências. Já no pós-teste, dos 47 usos 44 atendiam às exigências quantos às três relações grafofonológicas em estudo. Em termos percentuais, houve um decréscimo de $72 \%$. O aluno 03 , ainda que tenha usado poucas palavras, grafou a metade delas de forma incorreta. Após as intervenções, obtivemos um uso mais produtivo dessas palavras com uma quantidade bem pequena de incorreções. Nos dois outros casos, também obtivemos reduções importantes de 40\% para $14 \%$ e de $41 \%$ para $16 \%$. 


\section{Conclusões}

A pesquisa aqui apresentada cumpriu seus objetivos, pois A) investigou os casos mais frequentes de desvio à norma na escrita dos alunos, chegando ao tratamento do apagamento do $<\mathrm{r}>$ em coda de verbos, da hipercorreção da grafia da coda de verbos terminados em [w], e da monotongação de verbos no pretérito perfeito do indicativo; B) levou à elaboração e condução de atividades reflexivas com ênfase na relação grafema-fonema, que estão disponíveis em [link será adicionado na versão final]; e C) avaliou os efeitos da intervenção, verificando que a queda da quantidade de desvios atesta a validade do percurso pedagógico. Partimos de um panorama em que $26 \%$ dos usos relacionados ao grupo ortográfico analisado constituíam-se de erros para um quadro de $5 \%$ de ocorrências erradas nesse mesmo grupo.

Escrever pautado pelo que orienta a norma ortográfica da língua parece ser imperativo numa sociedade que valoriza a escrita como o espaço da verdade. Não possuir esse saber tido como legítimo pode ser motivo para desqualificar não só a variante linguística utilizada, mas aquele que a utiliza. À escola não cabe valorizar uma variedade de prestígio em detrimento de outras, mas oferecer a seus alunos condições de se apropriarem desse conhecimento legitimado para que tenham acesso aos bens de cultura por ela acessados.

Se tomarmos como parâmetros os dados gerais da pesquisa, verificamos a redução no número de erros em virtude de redução da seleção exclusivamente fonética dos vocábulos. Paralelo a isso, passou-se a observar os componentes morfológicogramaticais a eles relacionados. O apego à oralidade refletia, portanto, o pouco conhecimento sobre a estrutura e o funcionamento linguístico.

Restou-nos evidente, entretanto, que existe uma considerável lacuna entre o tratamento dispensado à ortografia no ensino fundamental I e no ensino fundamental II, porque são variados os erros de motivação fonético-fonológica que absorvem desde 
regularidades contextuais a irregularidades. Na modalidade EJA, apesar da reunião de percursos escolares diversos, também parece haver responsabilidades exclusivas de um e de outro segmento as quais inviabilizam um tratamento direcionado sobre o tema nos anos finais, pois se acredita ser de competência dos professores dos anos iniciais e, como resultado, os alunos acumulam dúvidas que se intensificam com o passar dos anos e geram inseguranças pela certeza de suas disparidades ortográficas.

Outra motivação possível para o quadro que se apresenta é talvez a crença de que nos anos finais as questões ortográficas serão superadas a partir do contato com os textos. A leitura seria suficiente para reverter dúvidas concernentes à grafia das palavras em um processo espontâneo que independe de sistematização. Essas medidas seriam sensatas se apenas restassem dificuldades irregulares, o que não representa o grupo em análise.

Por se tratar de uma turma dessa modalidade, a variedade de níveis de escrita se sobressai em comparação às salas de aula regulares, o que torna o trabalho do professor mais complexo. Soma-se a isso a desmotivação, a infrequência e demais aspectos que incidem diretamente sobre essa clientela. Todavia, trabalhos como este pode lançar uma luz sobre uma das dificuldades frequentes nessas turmas e uma aspiração comum aos alunos que se veem à margem no que se refere ao uso normatizado da língua escrita.

O que se espera que seja percebido é que é possível tratar questões ortográficas em sala de aula com poucos recursos e obter resultados positivos. As intervenções aqui realizadas constituem apenas modelos que podem ser melhorados, adaptados à realidade de cada sala de aula. Por isso, as atividades desenvolvidas estão disponibilizadas na íntegra no link [a ser inserido na versão final]. Importante é que os professores destinem tempo a um tratamento direcionado às necessidades dos alunos uma vez que se percebe, em todos os níveis de ensino, a presença de erros ortográficos 
que poderiam ser sanados através de atividades que não apenas verifiquem se os alunos sabem escrever, mas que os ensinem quando não sabem.

\section{Referências Bibliográficas}

BAGNO, M. Preconceito linguístico: o que é, como se faz. 49 ed. São Paulo: Loyola, 2007.

BORTONI-RICARDO, S. M. Educação em língua materna - a sociolinguística na sala de aula. São Paulo. Parábola Editorial, 2009.

BRASIL, Ministério da Educação/Inep. Mapa do analfabetismo no Brasil. Disponível em: www.portal.inep.gov.br.

CAGLIARI, L. C. Alfabetização e ortografia. Educar, Curitiba, Editora UFPR, n. 20, p. 43-58. 2002. DOI https://doi.org/10.1590/0104-4060.263

CAGLIARI, L. C. Alfabetizando sem o bá-bé-bi-bó-bu. São Paulo: Scipione, 1999.

FREIRE, P. A educação na cidade. 3. ed. São Paulo: Cortez, 1991.

GNERRE, M. Linguagem, escrita e poder. $4^{\underline{a}}$ ed. São Paulo: Martins Fontes, 1998.

KATO, M. A. No mundo da escrita: Uma perspectiva psicolinguística. 7 ed. São Paulo: Ática, 2009.

KLEIMAN, A. B. (org.). Os significados do letramento: uma nova perspectiva sobre a prática social da escrita. Campinas: Mercado das Letras, 2008.

LEMLE, M. Guia teórico do alfabetizador. - 17. ed. - São Paulo: Ática, 2007.

MORAIS, A. G.; LEAL, T. F.; ALBUQUERQUE, E. B. C. (Orgs.). Alfabetizar letrando na EJA: fundamentos teóricos e propostas didáticas. Belo Horizonte: Autêntica Editora, 2010.

MORAIS, A. G. Ortografia: ensinar e aprender. São Paulo: Ática, 2008.

MORAIS, A. G. O diagnóstico como instrumento para o planejamento do ensino de ortografia. In: SILVA, A. MORAIS, A. G.; MELO, K. L. R. (org.). Ortografia na sala de aula. Belo Horizonte: Autêntica, 2007a. p. 45-60. 
MORAIS, A. G.; SILVA, A. Ensinando ortografia na escola. In: MELO, K. L. R.; MORAIS, A. G.; SILVA, A. (org.). Ortografia na sala de aula. Belo Horizonte: Autêntica, 2007. P. 61-75

REGO, L. L. B. O aprendizado da norma ortográfica. In: MELO, K. L. R; MORAIS, A. G.; SILVA, A. (org.). Ortografia na sala de aula. Belo Horizonte: Autêntica, 2007.

ROBERTO, T. M. G. Fonologia, fonética e ensino: guia introdutório. São Paulo: Parábola Editorial, 2016.

SOARES, M. Alfabetização e letramento. 7. ed. São Paulo: Contexto, 2017.

SOUZA, O. Escrever na Escola: formação de cidadania e espaço para prosa de autor? Educação. Porto Alegre - RS, ano XXVII, n. 2 (53), p. 349 - 365, Mai./Ago. 2004. 